Louisiana State University

LSU Digital Commons

Faculty Publications

Department of Biological Sciences

$7-1-2008$

\title{
Weak competition among tropical tree seedlings: Implications for species coexistence
}

\author{
C. E.Timothy Paine \\ Louisiana State University \\ Kyle E. Harms \\ Louisiana State University \\ Stefan A. Schnitzer \\ Smithsonian Tropical Research Institute \\ Walter P. Carson \\ University of Pittsburgh
}

Follow this and additional works at: https://digitalcommons.Isu.edu/biosci_pubs

\section{Recommended Citation}

Paine, C., Harms, K., Schnitzer, S., \& Carson, W. (2008). Weak competition among tropical tree seedlings: Implications for species coexistence. Biotropica, 40 (4), 432-440. https://doi.org/10.1111/

j.1744-7429.2007.00390.x

This Article is brought to you for free and open access by the Department of Biological Sciences at LSU Digital Commons. It has been accepted for inclusion in Faculty Publications by an authorized administrator of LSU Digital Commons. For more information, please contact ir@lsu.edu. 


\title{
Marquette University \\ e-Publications@Marquette
}

Biological Sciences Faculty Research and

Publications

Biological Sciences, Department of

$7-2008$

\section{Weak Competition Among Tropical Tree Seedlings: Implications for Species Coexistence}

\author{
C.E. Timothy Paine \\ Louisiana State University \\ Kyle E. Harms \\ Smithsonian Tropical Research Institute \\ Stefan A. Schnitzer \\ Marquette University, stefan.schnitzer@marquette.edu \\ Walter P. Carson \\ University of Pittsburgh
}

Follow this and additional works at: https://epublications.marquette.edu/bio_fac

Part of the Biology Commons

\section{Recommended Citation}

Paine, C.E. Timothy; Harms, Kyle E.; Schnitzer, Stefan A.; and Carson, Walter P., "Weak Competition Among Tropical Tree Seedlings: Implications for Species Coexistence" (2008). Biological Sciences Faculty Research and Publications. 793.

https://epublications.marquette.edu/bio_fac/793 
Marquette University

e-Publications@Marquette

\section{Biological Sciences Faculty Research and Publications/College of Arts and Sciences}

This paper is NOT THE PUBLISHED VERSION; but the author's final, peer-reviewed manuscript. The published version may be accessed by following the link in the citation below.

Biotropica, Vol. 40, No. 4 (July 2008): 432-440. DOI. This article is (C) Wiley and permission has been granted for this version to appear in e-Publications@Marquette. Wiley does not grant permission for this article to be further copied/distributed or hosted elsewhere without the express permission from Wiley.

\section{Weak Competition Among Tropical Tree Seedlings: Implications for Species Coexistence}

\section{E. Timothy Paine}

Department of Biological Sciences, Louisiana State University, Baton Rouge, Louisiana

Kyle E. Harms

Department of Biological Sciences, Louisiana State University, Baton Rouge, Louisiana 70803, U.S.A. Smithsonian Tropical Research Institute, Apartado 2072, Balboa, Panama

Stefan A. Schnitzer

Smithsonian Tropical Research Institute, Apartado 2072, Balboa, Panama

Department of Biological Sciences, University of Wisconsin-Milwaukee, Milwaukee, Wisconsin

Walter P. Carson

Department of Biological Sciences, University of Pittsburgh, Pittsburgh, Pennsylvania 


\section{ABSTRACT}

The intensity of competition among forest tree seedlings is poorly understood, but has important ramifications for their recruitment and for the maintenance of species diversity. Intense competition among seedlings could allow competitively dominant species to exclude subordinate species. Alternatively, the low density and small stature of forest tree seedlings could preclude intense interseedling competition. In this case, other processes, such as size-asymmetric competition with adults, interactions with consumers, or neutral dynamics would prevail as those structuring the forest understory. We tested the intensity of, and potential for, intraspecific competition among tree seedlings of three species (Brosimum alicastrum, Matisia cordata, and Pouteria reticulata) in two Neotropical rain forests. We reduced stem densities by up to 90 percent and monitored individual growth and survival rates for up to $24 \mathrm{mo}$. Individual growth and survival rates were generally unrelated to stem density. Contrary to the predicted behavior of intensely competing plant populations, the distribution of individual heights did not become more left-skewed with time for any species, regardless of plot density; i.e., excesses of short, suppressed individuals did not accumulate in high-density plots. We further measured the overlap of zones of influence (ZOIs) to assess the potential for resource competition. Seedling ZOls overlapped only slightly in extremely dense monodominant plots, and even less in ambient-density plots of mixed composition. Our results thus suggest that interseedling competition was weak. Given the low density of tree seedlings in Neotropical forests, we infer that resource competition among seedlings may be irrelevant to their recruitment.

How the intensity of competition varies within and among the ontogenetic stages of forest trees is poorly known. Whether competition occurs only between seedlings and adults or additionally among seedlings of similar size has important ramifications for forest regeneration and the maintenance of species diversity. If competition is predominantly size-asymmetric; i.e., the most intense competition is that imposed by adults upon nearby seedlings, then seedling species identity would be relatively unimportant to individual performance, because seedlings would not compete intensely among themselves for resources (Lewis \& Tanner 2000, Barberis \& Tanner 2005). On the other hand, if seedlings of relatively similar sizes compete intensely among themselves, then the identity of neighboring seedlings may be an additional, critical determinant of individual performance, and seedlings themselves may partition resources (Tilman 1982), as many models of plant species coexistence assume (e.g., Pacala et al. 1996). No author, to our knowledge, has strongly promoted the idea that forest tree seedlings frequently compete among themselves. Nevertheless, because competition has been long understood to influence community structure and dynamics, understanding how the intensity of competition shifts among ontogenetic stages would provide insight into the ecology of forest trees.

Experiment and observation suggest that most competition in tropical forests is size-asymmetric. There is abundant evidence that shading by saplings and adults reduces the growth and survival of forest tree seedlings through above- and belowground competition (Marquis et al. 1986, Lewis \& Tanner 2000, Barberis \& Tanner 2005). In part due to asymmetric competition with adults, the density of seedlings in many closed-canopy forests is relatively low (Harms et al. 2004, Moles \& Westoby 2004; Table 1). Observing the paucity of seedlings in the understory of tropical forests, Wright (2002) conjectured that interseedling interactions could be sufficiently weak to allow the coexistence of every species able to tolerate the abiotic conditions of the understory, so long as frequency dependence kept the rarest from drifting to extinction.

Table 1. Seedling densities in high-density experimental plots and in 11 Neotropical rain forests. Densities of woody dicots (plus juveniles of canopy palms) 10-50 cm tall are sorted by decreasing density. Study plots were significantly denser than mixed-species plots (ANOVA of weighted means: $F_{2,14}=31.9, P<0.0001$ ). All sites receive at least $2200 \mathrm{~mm}$ of rainfall annually. Plot sizes ranged from 0.5 to $5 \mathrm{~m}^{2}$, but densities are scaled to 1 $m^{2}$ for ease of comparison. 


\begin{tabular}{|c|c|c|c|}
\hline Site & $\begin{array}{l}\text { Individual } / \mathrm{m}^{2} \text { (Mean } \pm \\
\mathrm{SD} \text { ) }\end{array}$ & $\begin{array}{l}\text { Number of } \\
\text { plots }\end{array}$ & Reference \\
\hline \multicolumn{4}{|l|}{ High-density plots } \\
\hline Pouteria reticulata, $\mathrm{BCl}$, Panama & $168.7 \pm 18.0$ & 16 & This study \\
\hline $\begin{array}{l}\text { Brosimum alicastrum, } \mathrm{BCl}, \\
\text { Panama }\end{array}$ & $56.3 \pm 10.0$ & 13 & This study \\
\hline Matisia cordata, CCBS, Peru & $52.7 \pm 19.7$ & 32 & This study \\
\hline \multicolumn{4}{|l|}{ Mixed-species plots } \\
\hline Paracou, French Guiana & $18.5 \pm 7.9$ & 60 & C. Baraloto (pers. comm.) \\
\hline CCBS, Peru & $6.4 \pm 4.8$ & 300 & Harms et al. (2004) \\
\hline $\mathrm{BCl}$, Panama & $6.1 \pm 1.5$ & 300 & Harms et al. (2004) \\
\hline $\begin{array}{l}\text { Estación Biologica Los Amigos, } \\
\text { Peru }\end{array}$ & $6.0 \pm 5.7$ & 192 & $\begin{array}{l}\text { C. E.T. Paine unpublished } \\
\text { data }\end{array}$ \\
\hline Yasuni, Ecuador & $6.0 \pm 11$ & 600 & M. Metz (pers. comm.) \\
\hline Km 41, Brazil & $5.6 \pm 2.1$ & 300 & Harms et al. (2004) \\
\hline $\begin{array}{l}\text { Beni, Bolivia (occasionally } \\
\text { hunted) }\end{array}$ & $4.2 \pm 0.1$ & 229 & $\begin{array}{l}\text { Roldan and Simonetti } \\
(2001)\end{array}$ \\
\hline Beni, Bolivia (intensively hunted) & $3.9 \pm 0.2$ & 238 & $\begin{array}{l}\text { Roldan and Simonetti } \\
(2001)\end{array}$ \\
\hline $\begin{array}{l}\text { La Virgen de Sarapiquí, Costa } \\
\text { Rica }\end{array}$ & $2.6 \pm 0.1$ & 144 & Capers et al. (2005) \\
\hline La Selva, Costa Rica & $2.0 \pm 1.0$ & 120 & Nicotra et al. (1999) \\
\hline Cay Rica, Costa Rica & $1.5 \pm 1.0$ & 117 & Nicotra et al. (1999) \\
\hline Chilamate, Costa Rica & $1.4 \pm 0.8$ & 107 & Nicotra et al. (1999) \\
\hline La Selva, Costa Rica & $1.1 \pm 0.7$ & 300 & Harms et al. (2004) \\
\hline
\end{tabular}

Very few studies have directly assessed the intensity of or potential for interseedling competition. High rates of frequency-dependent mortality befall tree seedlings, increasing diversity (Webb \& Peart 1999, Harms et al. 2000). This mortality may be caused by pathogens or predators (Freckleton \& Lewis 2006, Paine \& Beck in press), but is also consistent with intense competition. Interseedling competition was intense in high-density masting populations of Acer saccharum seedlings (Taylor \& Aarssen 1989), but appeared weak in a study of tropical tree seedlings (Brown \& Whitmore 1992). Because the selection pressures experienced by seedlings have long-lasting effects on tree species (Poorter 2007), determining the intensity of resource competition among seedlings is essential to understanding the coexistence of tropical trees.

In this study, we assess the intensity of, and potential for, competition among tree seedlings in the understory of two tropical rain forests. We test the relationship between performance (growth and survival) and population density in seedlings of three common species. We predicted that intense competition among neighbors would generate an inverse relationship between population density and seedling performance. The low density of tree seedlings we observed in the shaded understory of closed-canopy tropical rain forests initially motivated us to question the intensity of interseedling competition (e.g., Harms et al. 2004), but it is not known whether this low density may be a result of competition. As competition is predicted to be most intense in high-density populations, we chose to study the densest patches of naturally established seedlings available in Panamanian and Peruvian rain forests. Our study plots, which were dominated by one of three species, were more than an order of magnitude denser than the mixed-species seedling layer typical of Neotropical forests (95.0 \pm 66.0 vs. $4.4 \pm 4.5$ individuals $/ \mathrm{m}^{2}$ [weighted mean $\pm \mathrm{SD}$ ]; Table 1 ). If competition is found to be weak in such high-density plots, it is unlikely to be intense where seedling density is lower, regardless of species composition. We use three approaches to assess the potential for, and intensity of competition among seedlings: experimental 
reductions in plot density, estimates of the overlap of zones of influence (ZOIs), and calculations of temporal shifts in the distribution of plant heights.

\section{METHODS}

\section{Study site and species}

We investigated intraspecific competition among naturally established seedlings at Barro Colorado Island (BCl), Panama and Cocha Cashu Biological Station (CCBS), Peru. Descriptions of the flora and fauna of the two sites can be found in Croat (1978) and Gentry (1990), respectively. Annual rainfall averages 2600 and $2200 \mathrm{~mm}$ at BCl and CCBS, respectively. At $\mathrm{BCl}$, we performed density-reduction experiments on plots dominated by naturally recruited Brosimum alicastrum Sw. (Moraceae) and Pouteria reticulata (Engl.) Eyma (Sapotaceae), whereas similar manipulations were performed at CCBS on plots dominated by Matisia cordata Bonpl. (Bombacaceae). All three species are widespread and moderately common, distributed from Panama through southeastern Peru. Henceforth, we refer to them by their generic names. Pouteria and Matisia are canopy trees, whereas Brosimum is at times a canopy emergent. All three species are moderately shade tolerant; none are pioneer species (Croat 1978, Foster \& Janson 1985).

\section{Experimental reductions in plot density}

Density-reduction experiments were performed beneath adult trees that had fruited within the previous year. All seedlings were of similar sizes at the initiation of the density-reduction experiments. We assumed that seedlings were all the same age $(<1 \mathrm{yr})$, but seedling age was not possible to verify. At $\mathrm{BCl}$, we took advantage of an ongoing mammal-exclosure experiment, which was established in 1993. We excluded mammals from a large plot $(30 \times 45 \mathrm{~m})$ for $5 \mathrm{yr}$. We located a large, highly dense patch of naturally recruited Brosimum seedlings within the exclosure, and a separate one for Pouteria. In 1997, we established 13 and $161-\mathrm{m}^{2}$ plots haphazardly within these high-density patches of Brosimum and Pouteria seedlings, respectively. For both species, we randomly thinned the initially high-density plots to low, medium, or high (unmanipulated control) densities (15, 30, and 45-64 individuals $/ \mathrm{m}^{2}$, respectively). For Pouteria, patches of which were even more dense than those dominated by Brosimum, the unmanipulated control densities were of very high density (148-188 seedlings $\left(\mathrm{m}^{2}\right.$ ), and there were three treatments of experimentally reduced density (low, medium, and high). In Panama, we did not remove seedlings of other species, but there were so few of them that they were deemed unimportant. Density treatments were applied randomly to plots, which were separated by at least $1 \mathrm{~m}$. Seedling densities in the $\mathrm{BCl}$ forest during the previous several years had been approximately $30 / \mathrm{m}^{2}(\mathrm{~S}$. Schnitzer, pers. obs.), and our four treatment densities were designed to represent half of the median forest seedling density, median seedling density, high seedling density, and very high seedling density. Sample sizes for Brosimum plots were 4, 6, and 3 for low-, medium-, and high-density treatments, respectively; plots were evenly divided among treatments for Pouteria $(N=4)$.

In 2004 at CCBS, we located the eight Matisia adults with the densest patches of seedlings, separated by at least $250 \mathrm{~m}$. Beneath each adult, we established three $0.5-\mathrm{m}^{2}$ plots. We systematically selected and removed alternate seedlings to increase nearest-neighbor distances throughout each plot. Plots were thinned to low, medium, and high (unmanipulated control) densities (12, 24, and 40-112 individuals/ $\mathrm{m}^{2}$, respectively). Plots beneath each adult Matisia were separated by at least $2 \mathrm{~m}$, and were not protected from mammals. The 24 plots were evenly divided among treatments, one of each of which was located beneath each Matisia adult ( $N=$ 8).

At both sites and for all three species, we clipped seedling aboveground biomass without disturbing the soil, assuming that nutrient release from root decomposition was insignificant (Coomes \& Grubb 2000). No clipped seedlings of any species resprouted. All seedlings were independent of cotyledon reserves at the start of the 
experiments. Even so, subsidies from maternal reserves may mask the symptoms of competition. Young seedlings may translocate nonstructural carbohydrates from cotyledons into stems and roots, then utilize these stored reserves to withstand periods of negative carbon balance (Kitajima 1994). Symptoms of competition, such as density-dependent growth, would be masked until such subsidies were exhausted.

Brosimum and Pouteria seedlings were censused initially, and at 12 and 24 mo., whereas Matisia was censused at $0,8,13$, and 20 mo. At each census, we measured the height of the apical meristem of all living seedlings. In each census interval, we calculated the relative growth rate for individual height $\left(R G R_{h t}\right)$ as $\left(\ln \left(h_{t+1}\right)-\ln \left(h_{t}\right)\right) / T$, where $h$ is the individual's height in centimeters at censuses $t$ and $t+1$, and $T$ is elapsed time in days. Differences in individual $R_{G R}$ here compared among density treatments in linear mixed models for each species separately, blocked on plots. For Brosimum and Pouteria, survival rates were compared among treatments at each census in a linear model with a binomial error distribution. Because Matisia seedlings were censused three times, their survival functions could be estimated using the Kaplan-Meier method (Klein \& Moeschberger 1997). Matisia survival functions were compared with a log-rank test. Survival analyses were performed only on seedlings present in the initial censuses.

\section{The skewness of plant heights}

If competition were intense, the left-skewness of the distribution of plant heights would be expected to increase through time (Obeid et al. 1967). In dense plots, some individuals may acquire far fewer resources than their neighbors, causing them to grow substantially less. This would generate a long tail of relatively small individuals, i.e., left (or negative) skewness in the distribution of individual heights. We calculated the skewness of the distribution of stem heights per treatment at each census period (pooling over experimental replicates to achieve a reasonable sample size).

\section{The overlap of zones of influence}

Inferences on ZOIs provide a powerful approach to distinguish between the often confounded processes of resource competition and consumer-mediated (apparent) competition (Casper et al. 2003). Both resourcemediated and consumer-mediated competition may generate density dependence in individual performance. But resource competition additionally requires that the ZOls of two plants overlap and that their growth be resource-limited (Huston \& DeAngelis 1994), whereas individuals in 'apparent' competition may be spatially isolated (Holt 1977). Plant growth is almost always resource-limited, except following certain rare disturbances (Platt \& Connell 2003). Therefore, the potential for resource competition can be estimated by the extent of ZOI overlap. Following Huston and DeAngelis (1994), we define a ZOI as the area within which an individual plant may affect the availability of a limiting resource. Only if ZOIs overlap substantially may resource competition affect individual performance. All else being equal, increases in population density, individual size, and smallscale clumping cause greater ZOI overlap and thus intensify resource competition (Casper et al. 2003). Measurements of ZOIs may thus determine the potential for resource competition among plants.

We inferred the extents of ZOIs in two types of plots at CCBS, separate from the plots of the density-reduction experiment: high-density $0.5-\mathrm{m}^{2}$ Matisia-dominated plots $(N=7)$, and randomly located median-density 1$\mathrm{m}^{2}$ plots of mixed composition ( $\left.N=8\right)$. In Matisia-dominated plots, all Matisia seedlings were included in the analysis, and any non-Matisia seedlings (mean = 2.1 individuals per plot) were excluded; whereas in mixedspecies plots, all vascular plants were included.

ZOIs cannot be measured directly, but their extents may be inferred. Aboveground, we estimated aboveground ZOls as the overlap of leaves, which can be measured. We report leaf overlaps, rather than the extent to which seedlings shade each other, because the seedlings were of relatively uniform height $(16.9 \pm 3.8 \mathrm{~cm}$ [mean \pm SD]), and the relative height ranks of their leaves may be shuffled repeatedly over time. 
We assessed leaf overlaps photographically. A digital camera, equipped with a wide-angle lens, was mounted on a tripod and centered $2 \mathrm{~m}$ above the plot (see Connell et al. 1997, who developed the technique to study intertidal corals). The initial image documented the exposed leaf area of each seedling. We immediately clipped at the petiole and removed the uppermost leaves not overlapped by any other leaf. Another image was taken of the leaves thus revealed. The process was repeated up to six times until only bare stems remained. This final image mapped the location of each individual's point of contact with the ground. The leaf overlap of each seedling was calculated as the percentage of its leaf area overlapped by the leaves of other seedlings (Fig. 1). After we rectified the digital images in Adobe PhotoShop CS 8.0 (Adobe Systems, Inc. 2003) to remove lens distortions, we compared successive images to determine leaf overlaps in ImageJ 1.36b (Rasband 2005). Measurements of leaf overlaps by six people varied by $<5$ percent.

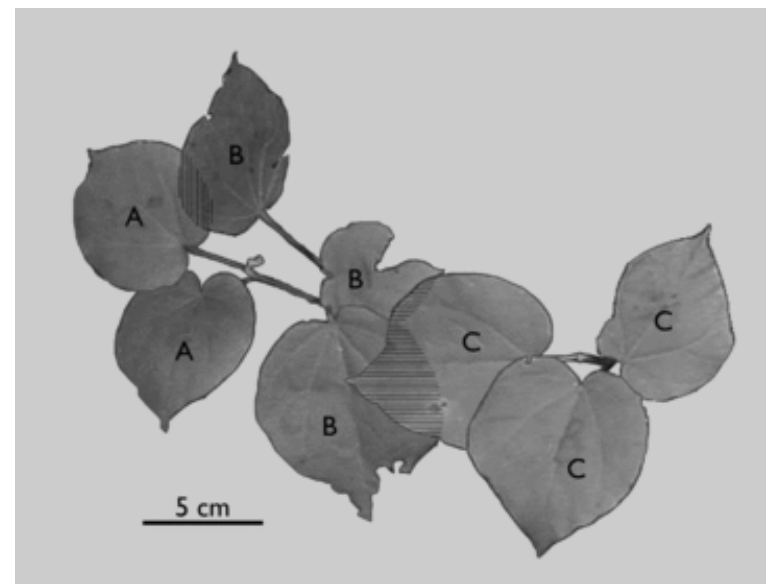

Figure 1. An illustration of the calculation of aboveground zone-of-influence overlaps. In this example, using Matisia cordata, the leaves of seedling B overlap those of both A and C. Vertical hatching indicates the area of overlap between $A$ and $B$, while horizontal hatching indicates $B$ and $C$ 's overlap. The $8.5 \mathrm{~cm}^{2}$ overlap of $A$ and $B$ represents four percent of A's leaf area and 3 percent of B's. The $43-\mathrm{cm}^{2}$ overlap of $B$ and $C$ represents 14 and 10 percent of $B$ and C's leaf area, respectively. The total aboveground overlap for $B$ is thus 17 percent. Overlap within an individual is not counted in zone-of-influence overlap.

The extent of an individual's belowground ZOI depends upon the supply rate of limiting resources, the rate at which the resources diffuse through soil, and the rate at which the individual takes up the resources (Huston \& DeAngelis 1994). An individual's belowground ZOI shrinks with increased resource supply rate, and expands with increases in resource diffusion rates and the individual's resource uptake rate. If diffusion or uptake rates are slow, an individual's ZOI will be restricted to the immediate vicinity of its roots. Because the soils underlying CCBS are clayey and relatively nutrient-rich (Osher \& Buol 1998), we assume that resource supply rates are relatively great, and diffusion is relatively slow.

To infer the extent of belowground ZOI overlap, we gently loosened the soil around each photographically mapped seedling, excavated it, and measured the extension of its lateral roots. Given the difficulty of precisely determining spatial relationships in the rhizosphere, we approximated a plant's belowground ZOI as a 'root-disk' centered at its stem with radius equal to the length of its longest lateral root (Casper \& Jackson 1997, Casper et al. 2003). Root-disk overlap was calculated using the mapped locations of seedlings and their root lengths (see Fig. 2 of Stohlgren 1993). An individual's pairwise overlaps were summed to calculate its overall root-disk overlap.

Several potentially offsetting biases may have affected our estimates of belowground ZOIs. Small seedlings of tropical trees bear few lateral roots, meaning that they occupy highly irregular polygons, the area of which is substantially smaller than our root-disks (Casper \& Jackson 1997). Moreover, root systems may vertically 
partition soil (Sala et al. 1989). Because root-disks lacked a depth component, we may further overestimate ZOI overlaps. On the other hand, our methods may have underestimated the radii of root-disks, as they were based on the lengths of lateral roots, which may have broken during excavation (Coomes \& Grubb 2000). We believe our estimates of root-disk overlaps to be conservative, as we likely overestimate the area of root systems. In estimating both above- and belowground ZOI overlaps, we strove to minimize the incidence of false negative results, the Type II error rate. All analyses were performed in R 2.3.1 (R Development Core Team 2006). All densities are reported per square meter for ease of comparison.

\section{RESULTS}

Over the 24-month experiment (20 mo for Matisia), seedlings grew, on average, $23-30 \mathrm{~cm}(30 \%), 21-26 \mathrm{~cm}$ (23\%), and 17-24 cm (40\%) for Brosimum, Pouteria, and Matisia, respectively. Simultaneously, seedlings experienced a substantial risk of mortality: only 76, 58, and 15 percent of seedlings survived through the experiment, respectively.

\section{Experimental reductions in plot density}

There was no general relationship between $\mathrm{RGR}_{\mathrm{ht}}$ and plot density. Brosimum $\mathrm{RGR}_{\mathrm{ht}}$ was unrelated to plot density in either census period, or overall $\left(F_{2,>290}<2.8, P>0.05\right.$; Fig. 2A). Pouteria RGR $R_{\text {ht }}$ did not differ among treatments after $12 \mathrm{mo}\left(F_{3,880}=1.6, P=0.18\right)$, but did after 24 mo and overall $\left(F_{3,>669}<4.3, P<0.005 ;\right.$ Fig. $\left.2 A\right)$. Surprisingly, Pouteria seedlings grew more rapidly in higher density plots, contrary to the prediction that competition among seedlings would reduce their growth in high-density plots. This positive density dependence suggests that these seedlings were in particularly favorable microsites or there was intraspecific facilitation (Klironomos 2002). Matisia RGR $\mathrm{ht}_{\mathrm{ht}}$ was unrelated to stem density in any of the three census periods of the 20-mo experiment, or overall $\left(F_{2,>48}<2.39, P>0.10\right.$; Fig. $\left.2 C\right)$. The significant decrease in Matisia heights between the 8and 13-month censuses may have been due to plants being damaged, but not killed, by falling debris. In sum, there was little evidence that reductions in seedling density increased seedling growth rates for the three species.

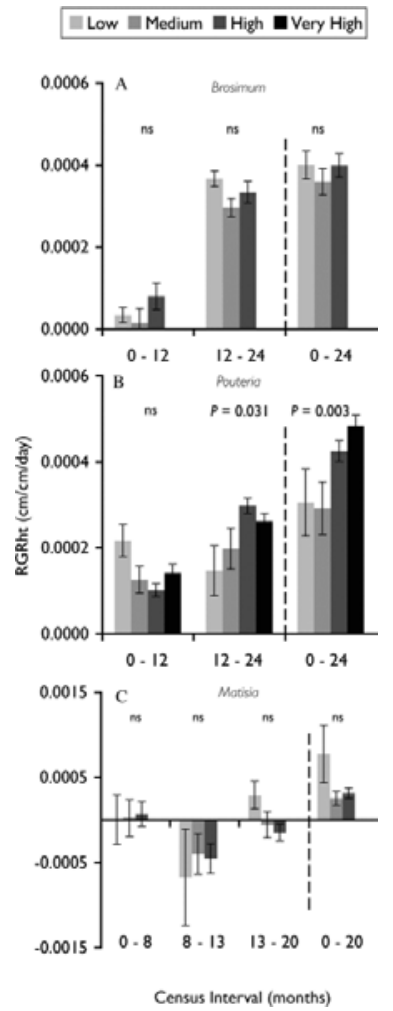


Figure 2. Relative height growth rate ( $\left.R G R_{h t}\right)$ of naturally established seedlings of $(A)$ Brosimum alicastrum, (B) Pouteria reticulata, and (C) Matisia cordata grown in plots of experimentally reduced density. Bars to the right of the vertical dashed line indicate $R G R_{h t}$ averaged over the course of the experiment. Bars indicate means $\pm 1 \mathrm{SE}$.

In some analyses, the variance in seedling survival was significantly explained by plot density. The survival of Brosimum seedlings did not differ among treatments in either census period or overall (deviance $<0.57, \mathrm{df}=$ $2, P>0.75$; Fig. 3A). Survival of Pouteria seedlings, on the other hand, differed significantly among density treatments over the 2-yr period (deviance $=14.00, \mathrm{df}=3, P=0.0029 ;$ Fig. 3B), though not in either 12-mo census interval (deviance $<6.53, \mathrm{df}=3, P>0.088$ ). This difference in survival was driven entirely by increased mortality in the very-high-density treatment, in which initial densities were an order of magnitude greater than the average total density of seedlings in Neotropical forests (Table 1). Matisia survival functions differed among treatments (Kaplan-Meier $\chi^{2}=124.7, P<0.0001$, Fig. 3C), but the final percentage of seedlings surviving through 20 mo did not $($ low $=0.06,95 \% \mathrm{Cl}=0.02-0.19$; medium $=0.13,95 \% \mathrm{Cl}=0.07-0.21$; high $=0.17,95 \% \mathrm{Cl}=0.13-$ 0.23). The differences in Matisia survival were driven by initially greater survival in high-density plots than in low- and medium-density plots - a pattern that ran counter to the prediction that competition among seedlings is intense. Overall, the lack of relationship between density and survival indicated that there was no competition among seedlings of the three species, except in extremely dense conditions.

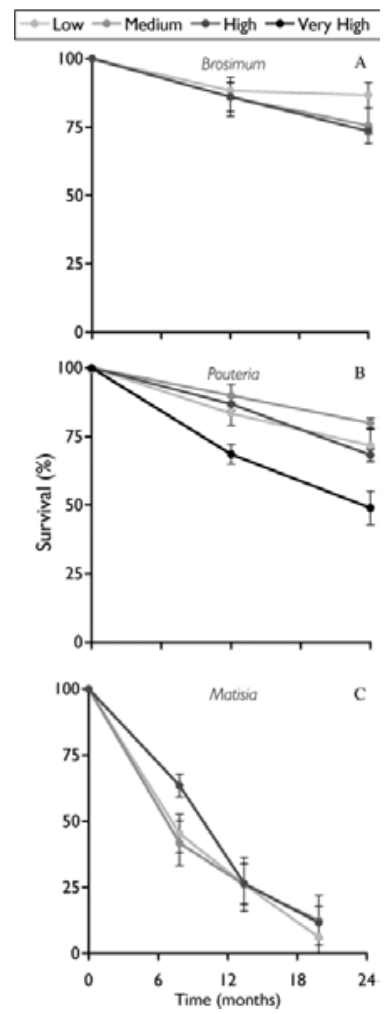

Figure 3. Survival of naturally established (A) Brosimum alicastrum, (B) Pouteria reticulata, and (C) Matisia cordata seedlings grown in plots of experimentally reduced density. Increased density reduced survival only for Brosimum, and only in extremely dense plots. Points indicate means $\pm 1 \mathrm{SE}$.

As an alternative estimate of the intensity of competition, we examined the skewness of the distribution of plant heights for each density treatment at each treatment period. Plant height skewness varied among treatments and censuses, but did not become more negative through time in any species, regardless of treatment density. 


\section{The overlap of zones of influence}

ZOI overlaps were inferred in high-density Matisia-dominated plots and in natural-density mixed-species plots. In Matisia-dominated plots, the overlap of both leaves and root-disks was minor, though seedling density was high (41.4 \pm 14.2 seedlings $/ \mathrm{m}^{2}$ ). Aboveground, each seedling overlapped a median of one other seedling (quartiles: 0-1), and experienced two percent leaf overlap (quartiles: 0-18\%; Fig. 4A). The leaves of approximately half of the seedlings did not overlap at all with those of their neighbors. Belowground, seedlings experienced a median of 13 percent root-disk overlap (quartiles: 0-38\%). The root-disks of 48 percent of individuals did not overlap at all with their neighbors, and just 18 percent of seedlings overlapped more than 50 percent with their neighbors (Fig. 4B).

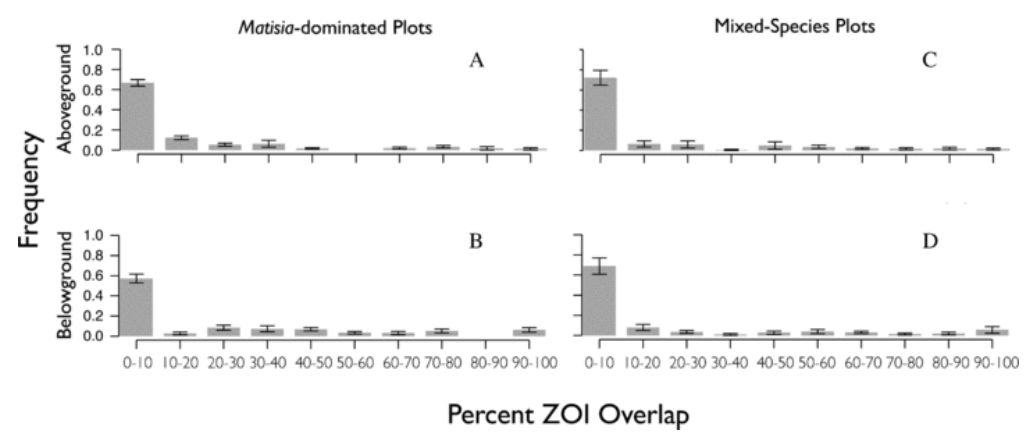

Figure 4. Histograms of aboveground zone of influence (ZOI) overlaps in (A) high-density, Matisia-dominated plots and (B) typical mixed-species plots. Belowground ZOI overlaps in (C) high-density, Matisia-dominated plots and (D) typical mixed-species plots. The ZOls of most seedlings do not overlap those of their neighbors, neither above- nor belowground, even in high-density plots. Bars represent the means of 7 and 8 plots $\pm 1 \mathrm{SE}$ for Matisia-dominated and mixed-species plots, respectively.

Leaf and root-disk overlaps in mixed-species plots were even less than in Matisia-dominated plots because of the overall lower density of seedlings ( $16.5 \pm 7.0$ individuals $/ \mathrm{m}^{2}$, including ferns and monocots). More than half (58\%) of individuals did not overlap whatsoever with other individuals aboveground (Fig. 4C). The median overlap of root-disks was 0 percent (quartiles: 0-40\%). Just 23 percent of seedlings overlapped more than 50 percent with their neighbors (Fig. 4D). Altogether, there was little potential for resource competition in highdensity Matisia-dominated plots, and even less in mixed-species plots of more typical density.

\section{DISCUSSION}

We infer that competition among seedlings of three species of rain forest trees was weak to nonexistent, and the potential for resource competition was slight, from the consistent results of three data sets: seedling performance, height skewness, and ZOI overlap. Seedling growth was at no time inversely related to plot density. Survival was inversely related to plot density for only one species, and only at densities an order of magnitude greater than typical (Fig. 3B). The distribution of plant heights did not become more left-skewed through time in high-density plots, contrary to the prediction that, in intensely competing populations, a small proportion of plants would be expected to grow vigorously while most remain small, as has been observed in experimental populations (especially annual herbs, e.g., Obeid et al. 1967). Too little investigation has been conducted on ZOI overlap and resource competition to understand their precise relationship, particularly in field conditions (Casper et al. 1998, 2003; Hawkes \& Casper 2002). For example, the degree of ZOI overlap required to generate intense resource competition is unknown. Nevertheless, when a majority of seedlings overlap neither the leaves nor the roots of their neighbors, the implication is that the potential for resource competition is low (Fig. 4). Furthermore, seedlings in Neotropical forests generally occur at densities an order of magnitude less than those of this study (Table 1). If competition among seedlings occurs broadly, it should have been 
detectable in this study. Thus we suggest that weak interseedling competition may be a general phenomenon in the shaded conditions of the tropical forest understory. Consistent with our assessment, the few studies that have studied competition between saplings and seedlings found it to be weak (Marquis et al. 1986), and those to have examined the mechanisms that generate density dependence in tropical forests have generally implicated pathogen attack or mammalian predation, rather than interseedling competition (Bell et al. 2006, Paine \& Beck in press).

The inference that competition among seedlings may be generally weak is subject to three caveats. First, this study examined seedlings of three species-a minute fraction of the tree diversity of most tropical forests. Experimentation with more species, particularly those with smaller seeds, would be valuable (Moles \& Westoby 2004). Second, inferences drawn from studies of intraspecific resource competition may not extend to species that differ widely in their tolerance of resource competition. Individuals of highly tolerant species may not exhibit intraspecific density-dependent growth or survival, while imposing resource competition on neighboring individuals of less-tolerant species. Experimentation on mixtures of species would be necessary for an explicit evaluation of interspecific competition. Third, our study plots were not randomly located throughout the study sites. They were located in the densest available patches of seedlings, which occurred beneath conspecific parental trees. To some degree, these sites were atypical, if for no other reason that, in the recent past, they were suitable sites for the recruitment of a conspecific individual. Investigations far from parental trees would allow an assessment of the relative roles of facilitation and competition.

\section{Competition among seedlings}

What reduced the intensity of competition among seedlings in this study? First, adult versus seedling resource competition is intense and highly asymmetrical (Coomes \& Grubb 2000). Light capture by canopy trees can reduce light availability in the understory to $<2$ percent of ambient levels (Canham et al. 1990, Montgomery \& Chazdon 2002), which keeps seedling growth rates well below those found in canopy gaps. Trenching experiments demonstrate that adults also suppress seedlings though belowground competition (Coomes \& Grubb 2000, Lewis \& Tanner 2000).

Second, a number of processes keep seedling densities low in forest understories, reducing opportunities for competition (Wright 2002, Moles \& Westoby 2004). These include consumers (pathogens, seed predators, and herbivores, Freckleton \& Lewis 2006, Paine \& Beck in press), and disturbance in the form of debris falling from the canopy (Clark \& Clark 1989). Brosimum and Pouteria, protected from mammalian herbivores, had substantially lower mortality rates than did Matisia, which was unprotected, suggesting that mammals may have killed some seedlings. The fall of debris from the canopy was also probably an important source of mortality, as many seedlings of all three species disappeared 'without a trace'. Host-specific pathogens are unlikely to have killed many of the seedlings in this study, since they typically cause negative density-dependent mortality, a pattern we did not observe.

Finally, one might suggest that competition among seedlings in the past may have reduced their density such that resource competition is currently weak. We find this unlikely, because seedlings in a newly recruited cohort are smaller and would have even less ZOI overlap than those in our study, and self-thinning typically does not lead to overcompensation (Yoda et al. 1963).

Competition among seedlings may intensify when one or more of these factors is weakened. For example, we observed negative density dependence in the survival of Pouteria seedlings only where their initial density was 10 times greater than the mean total density of the seedling layer and they were protected by mammal exclosures (Fig. 2B). Other situations where competition among seedlings may intensify, particularly belowground, are in treefall gaps, where survival and growth rates increase concomitantly with light availability 
(Schnitzer et al. 2005), or following community masting events, which can lead to extremely high seedling densities (Taylor \& Aarssen 1989).

\section{Competitive irrelevance}

The continuum of interactions proposed to occur among neighboring plants ranges from strict competitive hierarchies, which result in resource partitioning (Tilman 1982, Chase \& Leibold 2003), to competitive equivalence, which underlies neutral models (Pacala 1988, Hubbell 2006). Our results suggest a possible complementary condition: competitive irrelevance.

We suggest that competitive irrelevance may be a minimally interactive, unstable contributor toward coexistence. Under competitive irrelevance, neighboring individuals are isolated by distance such that, though species may differ in competitive ability, interactions among individuals are reduced in intensity. Spatial isolation thus imposes an 'equalizing force' (sensuChesson 2000) on the competitive ability of all individuals by effectively reducing the intensity of competition between neighboring plants to near zero. Coexistence would be unstable in that, in the absence of competition among individuals, all mortality would be density-independent, except for (potentially density-dependent) predation. Competitive irrelevance would thus facilitate unstable coexistence without the stringent and rarely realized requirement of strict competitive equivalence.

We emphasize that competitive irrelevance would apply only during a limited portion of any life cycle, and even then, only to individuals of relatively uniform size. Moreover, competitive irrelevance is most likely in habitats, such as the understory of closed-canopy forests, in which the density and growth rates of individuals are diminished by factors other than competition, as described above. Furthermore, competitive irrelevance makes no assumptions regarding the potential asymmetry of interactions that may occur during other phases of the life cycle, and the duration of the phase of competitive irrelevance remains to be investigated. As plants grow, competition may intensify, causing individual performance to decline and avoiding the infinite population sizes that are predicted in completely noninteractive models of coexistence (Caswell 1976).

Competitive irrelevance may describe the dynamics of tree seedlings in the shaded understory of tropical forests. If so, the consequences for species coexistence would be profound (Wright 2002, Poorter 2007). If competition among seedlings were absent or weak, other processes would by necessity prevail as those structuring the forest understory, such as neutral dynamics, size-asymmetric competitive hierarchies, fundamental niche requirements, or interactions with consumers. Hierarchies of competitive ability cannot give rise to competitive exclusion if potential competitors do not interact. A sufficient delay in the advent of intense competition within the members of a cohort could contribute to the maintenance of diversity in tropical forests. If reduced competition among individuals of the same ontogenetic stage led to the establishment of more species, diversity would be enhanced.

\section{ACKNOWLEDGMENTS}

We are grateful to Peru's Instituto Nacional de Recursos Naturales for allowing us permission to conduct research in Manu National Park. We thank C. Georghiou, N. Hidalgo, K. Schmitt, and P. Weisenhorn for their field assistance. Extensive discussions with J. Carlson, J. Myers, and M. Metz improved early drafts of this manuscript. C. Baraloto and M. Metz kindly shared unpublished results. Comments from C.O. Webb, H. Tuomisto, and two anonymous reviewers greatly strengthened the manuscript. The National Science Foundation (DEB 0211004 to KEH and DEB 0212054 and 9615184 to WPC), the Organization of American States, a Sigma Xi Grant-in-Aid-ofResearch, and the LSU Biology Graduate Student Association (BioGrads) supported this research. 


\section{References}

Barberis, I. M., and E. V. J. Tanner. 2005. Gaps and root trenching increase tree seedling growth in Panamanian semi-evergreen forest. Ecology 86: 667- 674.

Bell, T., R. P. Freckleton, and O. T. Lewis. 2006. Plant pathogens drive density-dependent seedling mortality in a tropical tree. Ecol. Lett. 9: 569- 574.

Brown, N. D., and T. C. Whitmore. 1992. Do dipterocarp seedlings really partition rainforest gaps? Philos. Trans. R. Soc. Lond. B 335: 369- 378.

Canham, C. D., J. S. Denslow, W. J. Platt, J. R. Runkle, T. A. Spies, and P. S. White. 1990. Light regimes beneath closed canopies and tree-fall gaps in temperate and tropical forests. Can. J. For. Res. 20: 620-631.

Capers, R. S., R. L. Chazdon, A. Redondo Brenes, and B. Vilchez Alvarado. 2005. Successional dynamics of woody seedling communities in wet tropical secondary forests. J. Ecol. 93: 1071- 1084.

Casper, B. B., J. F. Cahill, and L. A. Hyatt. 1998. Above-ground competition does not alter biomass allocated to roots in Abutilon theophrasti. New Phytol. 140: 231- 238.

Casper, B. B., and R. B. Jackson. 1997. Plant competition underground. Annu. Rev. Ecol. Syst. 28: 545-570.

Casper, B. B., H. J. Schenk, and R. B. Jackson. 2003. Defining a plant's belowground zone of influence. Ecology 84: 2313- 2321.

Caswell, H. 1976. Community structure-neutral model analysis. Ecol. Monogr. 46: 327-354.

Chase, J. M., and M. A. Leibold. 2003. Ecological niches: Linking classical and contemporary approaches. University of Chicago Press, Chicago, Illinois .

Chesson, P. 2000. Mechanisms of maintenance of species diversity. Annu. Rev. Ecol. Syst. 31: 343- 366.

Clark, D. B., and D. A. Clark. 1989. The role of physical damage in the seedling mortality regime of a Neotropical rain forest. Oikos 55: 225- 230.

Connell, J. H., T. P. Hughes, and C. C. Wallace. 1997. A 30-year study of coral abundance, recruitment, and disturbance at several scales in space and time. Ecol. Monogr. 67: 461- 488.

Coomes, D. A., and P. J. Grubb. 2000. Impacts of root competition in forests and woodland: A theoretical framework and review of experiments. Ecol. Monogr. 70: 171- 208.

Croat, T. B. 1978. Flora of Barro Colorado Island. Stanford University Press, Stanford, California .

Foster, S. A., and C. H. Janson. 1985. The relationship between seed size and establishment conditions in tropical woody plants. Ecology 66: 773- 780.

Freckleton, R. P., and O. T. Lewis. 2006. Pathogens, density dependence and the coexistence of tropical trees. Proc. R. Soc. B 273: 2909- 2916.

Gentry, A. H. 1990. Four Neotropical forests. Yale University Press, New Haven, Connecticut .

Harms, K. E., J. S. Powers, and R. A. Montgomery. 2004. Variation in small sapling density, understory cover and resource availability in four Neotropical forests. Biotropica 36: 40- 51.

Harms, K. E., S. J. Wright, O. Calderon, A. Hernandez, and E. A. Herre. 2000. Pervasive density-dependent recruitment enhances seedling diversity in a tropical forest. Nature 404: 493-495.

Hawkes, C. V., and B. B. Casper. 2002. Lateral root function and root overlap among mycorrhizal and nonmycorrhizal herbs in a Florida shrubland measured using rubidium as a nutrient analog. $A m$. J. Bot. 89: 1289- 1294.

Holt, R. D. 1977. Predation, apparent competition, and structure of prey communities. Theor. Popul. Biol. 12: 197- 229.

Hubbell, S. P. 2006. Neutral theory and the evolution of ecological equivalence. Ecology 87: 1387- 1398.

Huston, M. A., and D. L. DeAngelis. 1994. Competition and coexistence-the effects of resource transport and supply rates. Am. Nat. 144: 954-977.

Kitajima, K. 1994. Relative importance of photosynthetic traits and allocation patterns as correlates of seedling shade tolerance of 13 tropical trees. Oecologia 98: 419-428. 
Klein, J. P., and M. L. Moeschberger. 1997. Survival analysis techniques for censored and truncated data. Springer-Verlag, New York, New York .

Klironomos, J. N. 2002. Feedback with soil biota contributes to plant rarity and invasiveness in communities. Nature 417: 67-70.

Lewis, S. L., and E. V. J. Tanner. 2000. Effects of above- and belowground competition on growth and survival of rain forest tree seedlings. Ecology 81: 2525- 2538.

Marquis, R. J., H. J. Young, and H. E. Braker. 1986. The influence of understory vegetation cover on germination and seedling establishment in a tropical lowland wet forest. Biotropica 18: 273-278.

Moles, A. T., and M. Westoby. 2004. What do seedlings die from and what are the implications for evolution of seed size? Oikos 106: 193- 199.

Montgomery, R. A., and R. L. Chazdon. 2002. Light gradient partitioning by tropical tree seedlings in the absence of canopy gaps. Oecologia 131: 165- 174.

Nicotra, A. B., R. L. Chazdon, and S. V. B. Iriarte. 1999. Spatial heterogeneity of light and woody seedling regeneration in tropical wet forests. Ecology 80: 1908- 1926.

Obeid, M., D. Machin, and J. L. Harper. 1967. Influence of density on plant to plant variation in fiber flax, Linum usitatissimum L. Crop Sci. 7: 471-473.

Osher, L. J., and S. W. Buol. 1998. Relationship of soil properties to parent material and landscape position in eastern Madre de Dios, Peru. Geoderma 83: 143- 166.

Pacala, S. W. 1988. Competitive equivalence-the coevolutionary consequences of sedentary habit. Am. Nat. 132: 576- 593.

Pacala, S. W., C. D. Canham, J. Saponara, J. A. Silander, R. K. Kobe, and E. Ribbens. 1996. Forest models defined by field measurements: Estimation, error analysis and dynamics. Ecol. Monogr. 66: 1-43.

Paine, C. E. T., and H. Beck. 2007. Seed predation by Neotropical rainforest mammals increases diversity in seedling recruitment. Ecology. 88: 3076- 3087.

Platt, W. J., and J. H. Connell. 2003. Natural disturbances and directional replacement of species. Ecol. Monogr. 73: 507-522.

Poorter, L. 2007. Are species adapted to their regeneration niche, adult niche, or both? Am. Nat. 169: 433-442.

R Development Core Team . 2006. R: A language and environment for statistical computing. $R$ Foundation for Statistical Computing, Vienna, Austria .

Rasband, W. S. 19972005. ImageJ. U. S. National Institutes of Health, Bethesda, Maryland, USA , http://rsb.info.nih.gov/ij/

Roldan, A. I., and J. A. Simonetti. 2001. Plant-mammal interactions in tropical Bolivian forests with different hunting pressures. Conserv. Biol. 15: 617- 623.

Sala, O. E., R. A. Golluscio, W. K. Lauenroth, and A. Soriano. 1989. Resource partitioning between shrubs and grasses in the Patagonian steppe. Oecologia 81: 510- 505.

Schnitzer, S. A., M. Kuzee, and F. Bongers. 2005. Disentangling above-and below-ground competition between lianas and trees in a tropical forest. J. Ecol. 93: 1115- 1125.

Stohlgren, T. 1993. Intra-specific competition (crowding) of giant sequoias (Sequoiadendron giganteum). Forest Ecol. Manage. 59: 127- 148.

Taylor, K. M., and L. W. Aarssen. 1989. Neighbor effects in mast year seedlings of Acer saccharum. Am. J. Bot. 76: 546- 554.

Tilman, D. 1982. Resource competition and community structure. Princeton University Press, Princeton, New Jersey .

Webb, C. O., and D. R. Peart. 1999. Seedling density dependence promotes coexistence of Bornean rain forest trees. Ecology 80: 2006- 2017.

Wright, S. J. 2002. Plant diversity in tropical forests: A review of mechanisms of species coexistence. Oecologia 130: 1-14. 
Yoda, K., T. Kira, H. Ogawa, and K. Hozumi. 1963. Self-thinning in overcrowded pure stands under cultivated and natural conditions. J. Biol. 14: 107-129. 